\title{
Espacio público y espacio religioso en Chile republicano
}

Un destacado historiador del catolicismo norteamericano inició una conferencia sobre la religión y los conflictos internacionales ante 200 oficiales de las fuerzas armadas preguntándoles si habían rezado esa mañana. Se produjo un desconcierto y poco menos de la mitad levantó tímidamente la mano. Luego preguntó cuantos creían que esa era una materia que no le incumbía, y los 200 levantaron la mano con entusiasmo y alivio (1). Ellos -y con ellos la cultura occidental moderna- tienen internalizado la separación de la esfera pública y de la privada y la religión como un asunto privado cuyo libre ejercicio el poder público debe garantizar.

La relación entre espacio público y espacio religioso desde la perspectiva de la historia política requiere dos enfoques complementarios: el primero es que la política moderna, al separar el espacio público del privado, tiende a privatizar la religión y hacerla parte del dominio de la conciencia y de la práctica privada. El segundo es que la laicización del Estado en el XIX transforma el rol de la religión que se inserta de distinta forma en el espacio público moderno. En este breve artículo quisiéramos ejemplificar estos dos enfoques en el caso chileno luego de una crítica a las visiones clásicas sobre el tema.

\section{EL CANON DE LA HISTORIOGRAFÍA LIBERAL Y CONSERVADORA}

A mi juicio, y por paradójico que parezca, la historiografía latinoamericana no ha asumido la profunda historicidad del fenómeno de la secularización. Continúan latentes interpretaciones canónicas herederas de la interpretación liberal del siglo XIX. Si estudiamos la construcción de la nación moderna, la religión católica aparece como una de las fuerzas antagónicas que finalmente es derrotada. Entonces la religión pasa a ser un estudio de los especialistas de la historia de la Iglesia y sale del objeto de la historia política y social. Los historiadores han sido, en forma mas o menos explícita, seguidores de los fundadores de la sociología clásica en la cual la secularización era sinónimo no solo de la privatización de la religión, sino también de su decadencia.

(1) R. Scott Appleby, The Ambivalence of the Sacred, Carnagie Comission on Preventing Deadly Conflict, Rowman \& Littlefield Publishers, USA, 2000, p. 1. 
La laicización del Estado es uno de los temas fundantes de la historiografía tradicional chilena y el que separa la escuela conservadora de la liberal en el siglo XX. Ambas se identifican con la formación del Estado nacional y con la Independencia, pero interpretan desde ángulos opuestos el sentido de la historia del siglo XIX. Si para la liberal es una historia política que relata el progresivo ensanche de la libertad y de la tolerancia, de la autonomía de la razón de la sujeción religiosa y del Estado de la Iglesia, para la historiografía conservadora es la historia de la pérdida de poder del Estado central autoritario que se disuelve en el partidismo liberal primero y democrático después. A la pregunta de por qué Chile fue el primer Estado nacional del continente en consolidarse como tal después de la Independencia, la respuesta es clara: porque la República Conservadora (1830-1861) habría sido la continuación del Estado español católico centralizado y autoritario, aunque su fundamento no fuera religioso sino jurídico. La decadencia de Chile no viene de la República, sino de la secularización, de la separación de las esferas religiosa y civil que es la que permite una sociedad plural. Es ese pluralismo liberal, descrito como partidismo, el que mina las bases del poder del Estado, quiebra la unidad nacional e inicia la decadencia (2). Entonces, la historiografía conservadora y la liberal coinciden en el supuesto que planteo desde su fundación la sociología de que la separación de la esfera religiosa de la civil significaba no solo la privatización de la religión, sino su necesaria decadencia. Con un cierto criterio evolutivo, la religión, sería algo que finalmente tendería a desaparecer del dominio público.

Esta visión esta latente en gran parte de nuestra historia política y aun en nuestra historia religiosa del periodo moderno. Las críticas a las teorías de las secularización dentro de la sociología, la evidencia de la importancia que hoy tiene la religión en los asuntos internacionales, los estudios que indicarían que la decadencia fue un fenómeno europeo pero no americano, africano y asiático, nos obliga a lo evidente: historizar la secularización (3). Es lo que creo que está pasando en nuestra historiografía regional, quizás más fruto de la renovación de la historia política que de una critica explícita a las teorías sociológicas de la secularización (4).

(2) Los principales exponentes de la historiografía conservadora son Alberto Edwards, La fronda aristocrática (Editorial Universitaria, 10 edición, Santiago, 1987). Jaime Eyzaguirre, Fisonomía histórica de Chile (Editorial Universitaria, Santiago, 1948). Mario Góngora, Ensayo histórico sobre la noción de Estado en Chile en los siglos XIX y XX (Editorial Universitaria, segunda edición, 1986). Gonzalo Vial, Historia de Chile (Editorial Santillana, Santiago, 2 vols., 1981). Para un estudio crítico de dicha historiografía véase Renato Cristi y Carlos Ruiz, El pensamiento conservador en Chile (Editorial Universitaria, Santiago, 1992). Para la historiografîa liberal ver, por ejemplo, a Domingo Amunátegui Solar, El progreso intelectual y político de Chile, Editorial Nascimento, Santiago, 1936; Ricardo Donoso, Las ideas políticas en Chile, Editorial Eudeba, Buenos Aires, 1975; Julio Heise, Historia de Chile. El período parlamentario 1861-1925, Editorial Andrés Bello, Santiago, 1974.

(3) José Canovas, Public Religions in the Modern World (The University of Chicago Press, Chicago and London, 1994), 6.

(4) La renovación historiográfica ya ha comenzado y se expresa en historias generales o compilaciones tales como Roberto di Stefano y Loris Zanatta, Historia de la Iglesia Argentina. Desde la Conquista hasta fines del siglo XX, Grijalbo Mondadori, Buenos Aires, 2000; Manuel Ramos Medina (comp.), Historia de la Iglesia en el siglo XIX, CONDUMEX, México DF,1998; Brian F. Connaughton y Andrés Lira González, Las fuentes eclesiásticas para la historia social de México, Universidad Autónoma Metropolitana, Instituto Mora, México DF, 1996; Fernando Armas Asín (comp.), La construcción de la Iglesia en los Andes, P. Universidad Católica de Lima, Lima,1999; Auesten Ivereigh (ed.), The Politics of Religion in an Age of Revival, Institute 


\section{LIBERTAD DE CULTO Y PUBLICIDAD MODERNA}

Desde la perspectiva de la renovación de la historia política, el primer paso puede ser volver al conflicto clásico entre Iglesia y Estado en el XIX con nuevos ojos. Y como suele suceder, quizás la mirada más novedosa sea la de los propios actores. Sabemos que la Independencia fue un conflicto político y no religioso, aunque este estaba latente al transformar el principio legitimador del poder de un fundamento religioso a uno jurídico. La periodificación en el continente es distinta, pero podemos convenir que hacia mediados de siglo el problema ya estaba instalado en la política latinoamericana (5). No podía no estarlo, era inherente a la construcción de la soberanía nacional combatir cualquier otro poder que reclamara soberanía por sobre ella. La gran pregunta que recorre el siglo es cuál era el papel público de la Iglesia en un sistema republicano que mantuvo luego de la Independencia la unión entre Iglesia y Estado.

En el caso chileno, los actores políticos se preguntaron exactamente esa pregunta: qué es lo publico y qué es lo privado. La laicización significaba estrechar la frontera de lo público para dejar a la iglesia en el ámbito de lo privado. La Constitución de 1833 establecía en su artículo quinto que el Estado de Chile era católico y que se prohibía el culto "público" de cualquier otra confesión. Ello significaba que los pequeños grupos disidentes no podían tener templos que evidenciaran su calidad de tal ni escuelas que enseñaran su doctrina ni cementerios, pues todos eran católicos. Hubo tolerancia práctica, pero los conflictos fueron creciendo en la medida en que el liberalismo ascendía. Esto ponía problemas muy diversos, desde cómo se iba a enterrar a los protestantes o ateos en cementerios benditos (se diseñó un espacio apartado del cementerio con una reja de un metro de separación), hasta si los templos protestantes podían tener torres visibles desde la calle o si los anglicanos podían tocar sus campanas o tener escuelas. Ese fue el debate en 1865 para establecer la tolerancia religiosa. Los liberales sostuvieron que lo público era lo estatal y solo estatal, por tanto el Estado podía ser católico -cuestión que preferían para no perder su dominio a través del patronato- pero no tenía por qué serlo la sociedad que podía profesar libremente otros cultos. La Iglesia dirá que lo público no es solo lo estatal, sino todo espacio social. Solo el espacio doméstico y la conciencia eran privados. Esta segunda interpretación no hacía posible el pluralismo religioso y la Iglesia se opuso (6). Es por ello que, desde una perspectiva ideológica, el catolicismo no pudo ser sino considerado antimoderno, aunque en el caso latinoamericano fue siempre republicano y no monárquico.

La Iglesia se opuso al pluralismo religioso y con ello a un principio esencial de la esfera pública moderna. Pero el catolicismo, queremos proponer, se readapta y lucha por su organización en la sociedad civil. Como sucedió en tantos países, el ultramontanismo católico fue la lucha por la independencia de la Iglesia en contra

of Latin American Studies, University of London, London, 2000. Gardenia Vidal y Pablo Vagliente (comp.), Por la señal de la Cruz. Estudios sobre Iglesia católica y sociedad en Córdova, S. XVII-XX, Ferreira Editor, Argentina, 2002.

(5) Leslie Bethell (ed.) "La Iglesia Católica en América Latina,1830-1930", Historia de América Latina, Tomo VIII, Ed. Crítica, p. 65.

(6) Sol Serrano, "La definición de lo público en un Estado católico”, Estudios Públicos 76 (Santiago, 1999), 212-232. 
del Estado, y lo interesante es que peleó haciendo uso de los derechos que ese mismo Estado le otorgaba.

\section{EL CATOLICISMO EN LA SOCIEDAD CIVIL}

La interpretación canónica sobre la formación del Estado nacional en Chile reza que las fuerzas liberales lograron progresivamente carcomer el autoritarismo presidencialista ampliando las libertades individuales y las prerrogativas del Parlamento. Las libertades se habrían conquistado en contra del gobierno y en contra de la Iglesia. Ello fue efectivamente así, pero simplifica el rol jugado por los conservadores católicos en ese mismo orden liberal. No se incorpora la paradoja de que los conservadores lucharon en contra del Estado liberal tratando de ampliar sus propios espacios de libertad. La coyuntura crítica desde la perspectiva de la historia política fueron las reformas constitucionales de la década de 1870. Ni la historiografía liberal, que considera esa coyuntura como el clímax del ascenso liberal, ni la historiografía conservadora que la considera el inicio de la ruptura de la unidad nacional, repararon que los conservadores habían tenido un papel muy importante en reformas claves como la supresión del voto censitario y la consagración de la libertad de asociación como una garantía constitucional (7). Resulta sorprendente volver a las fuentes y constatar que esta última reforma significó un intenso debate entre liberales y conservadores, pues estos últimos querían ir más lejos e incorporar el derecho de asociación sin permiso previo y que toda sociedad tuviera personería jurídica sin necesidad de pedir autorización estatal (8). No lo lograron. Pero surge evidentemente la pregunta de por qué los conservadores católicos tomaron la bandera de la libertad de asociación, una reivindicación tan clásicamente liberal. Los conservadores católicos estaban defendiendo un mundo asociativo denso y diverso que temían fuera controlado y, peor aún, expropiado por el Estado. Era un mundo que comprendía a las cofradías, pero que ya no eran las mismas que las cofradías coloniales. Un nuevo mundo asociativo católico también había surgido junto a las nuevas sociabilidades políticas y filantrópicas.

Las fuentes para el estudio de cofradías en países en que los bienes eclesiásticos no fueron expropiados tienen muchas dificultades. Considerando las limitaciones, hemos construido un catastro de las asociaciones católicas entre 1830 y 1890 en el Arzobispado de Santiago (9).

(7) Samuel Valenzuela, Democratización vía reforma: la expansión del sufragio en Chile (Editorial IDES, Buenos Aires, 1985). J. Samuel Valenzuela and Erica Maza Valenzuela, "The Politics of Religion in a Catholic Country: Republican Democracy, Cristianismo Social and the Conservative Party in Chile, 1850-1925”, en Austen Ivereigh (ed.), The Politics of Religion in an Age of Revival, Institute of Latin American Studies, University of London, London, 2000.

(8) Sol Serrano, "La estrategia conservadora ante la consolidación del Estado Liberal en Chile, 18601890", Marcello Carmagani (editor), Constitucionalismo y Orden Liberal 1850-1920, Centro de Estudios de México en Italia, Universidad de Torino, Torino, 2000.

(9) El catastro se ha formado en base a una multiplicidad de fuentes. Las más relevantes manuscritas son los documentos en el Archivo del Arzobispado de Santiago relativo a la correspondencia entre el Arzobispado y diversas cofradías; las Visitas Pastorales de los Arzobispos Manuel Vicuña, Rafael Valentín Valdivieso y Manuel Casanova y la publicación periódica del Arzobispado, Boletín Eclesiástico, con todos los decretos y documentos oficiales de la diócesis. 
La primera afinación que permite hacer es que el asociacionismo católico fue un fenómeno cuantitativamente significativo: fueron encontradas 309 asociaciones en la diócesis de Santiago. La segunda es que crece a lo largo del siglo, siendo la década de 1880 un momento álgido de fundaciones. Es un universo muy heterogéneo que describe experiencias distintas, pero el tamaño indica al menos que el asociacionismo católico numéricamente supera con creces a todas las otras formas asociativas de la época, las logias masónicas, los clubes, o las mutuales de fines de siglo.

La tercera afirmación es que las cofradías -entendidas como asociaciones católicas laicas de fieles que se reúnen con el fin de practicar una devoción religiosa y otorgar servicios religiosos a sus asociados-, lejos de ser un fenómeno solo de herencia colonial, es también un fenómeno del siglo XIX. Si bien las fuentes no permiten establecer la fecha exacta de fundación de todas, es posible saber en qué período fueron fundadas la mayoría de ellas. En nuestra muestra, solo un $9 \%$ de las asociaciones son cofradías fundadas en la colonia y un $63 \%$ en el periodo republicano. No tenemos información para un $28 \%$. Surge la pregunta de qué pasó con las cofradías coloniales, pero esa no es la nuestra por ahora. Nuestro interés reside en poder afirmar categóricamente que el asociacionismo católico es un fenómeno activo en el siglo XIX y que tiene características propias de su tiempo.

La cuarta afirmación es que todas las formas de asociación crecen en el período, tanto las cofradías como las sociedades de beneficencia. Las primeras siguen siendo mayoritarias a lo largo del siglo (222 de 309) y las segundas crecen ostensiblemente en la segunda mitad.

Así como la base de datos no hace sino confirmar la profunda segregación urbano rural, matiza en algo la centralización de Santiago. Del total tenemos que 100 están en Santiago y 207 en el resto del obispado. Las asociaciones no fueron solo un fenómeno de ciudades propiamente tales, sino también de villas y de pueblos.

Si las asociaciones son un fenómeno segregado entre ciudad y campo, tiende también a segregar en materia de género. Las cofradías tradicionales eran en su gran mayoría mixtas, como lo eran las Órdenes terceras. Es en la segunda mitad del siglo donde aparece con más fuerza la separación de género. Si las cofradías siguieron siendo mixtas con un leve repunte de las femeninas, las sociedades de beneficencia -las que están actuando en el espacio público político y social y en el sector privado económico- son mayoritariamente masculinas. Las hay femeninas, pero tiende a no haber mixtas. Las sociedades son segregadas, al contrario de las cofradías que son integradoras en materia de género.

Las asociaciones católicas entre 1830 y 1890 muestran una clara tendencia al reforzamiento del poder parroquial y episcopal por sobre las Órdenes religiosas. No es casualidad que la Archicofradía del Santísimo Sacramento, que actúa de apoyo a la iglesia parroquial, sea la que más se repite en la diócesis . Por último, se percibe a través de las asociaciones cómo ascienden las nuevas devociones principalmente la del Sagrado Corazón y la Inmaculada Concepción, y ascienden nuevos santos que no son los coloniales, como San José, identificado con el artesanado urbano, y San Vicente, con los pobres urbanos.

Las cofradías siguieron siendo un fenómeno vivo y activo del siglo XIX y se diferencian de las coloniales en que no tienen un carácter gremial ni étnico. Las principales cofradías son interclases, las dirige la elite y forman parte de ellas mu- 
chos sectores diversos. Hay cofradías interclase y hay cofradías populares. No hay cofradías solo de la elite, pues el pueblo participa organizadamente en la fiesta patronal, donde se asienta masivamente. En todas las funciones del culto y la preparación de la fiesta son su objeto principal. Tanto en las urbanas como en las rurales. Las cofradías tienden a hacerse progresivamente más arraigadas a la parroquia y terminan muchas por ser como juntas de fábrica. Todas también tienen deberes y derechos que obligan a los asociados. Así como la cofradía presta servicios a la parroquia, presta servicio a los cofrades con asistencia sacramental para un mejor morir: la comunión en enfermedad grave y el entierro además de las misas por su alma para pasar el purgatorio. Queremos sugerir que el seguro de entierro y salvación espiritual que otorgaba la cofradía enfrenta graves dificultades de administración en la medida en que la economía se hace monetaria y que la sepultura adquiere un valor de mercado.

Las cofradías no mueren sino que pierden su importancia relativa ante dos tipos de organizaciones que eran nuevas en la realidad chilena: las asociaciones piadosas masivas asentadas parroquialmente o en congregaciones religiosas que se diferencian de las cofradías por no tener una transacción monetaria de un servicio. Este tipo de asociación es mayoritariamente devota al culto del Sagrado Corazón y a la Inmaculada Concepción.

La segunda nueva forma de asociación católica que surge en el siglo son las sociedades de beneficencia o asociaciones de caridad. Tal como las cofradías, ellas mantienen ritos comunes, pero tienen una diferencia esencial: el fin material de los asociados no son los asociados mismos sino los pobres, aunque el fin espiritual fueran ellos mismos. En las cofradías chilenas prácticamente no hubo caridad externa sino solo interna entre los cofrades en enfermedad y muerte. Al contrario de México y España, no he encontrado cofradías ligadas a hospitales, aunque sí legados y capellanías (10). Fruto del catolicismo ilustrado primero y de la reorganización eclesiástica apoyada por las congregaciones apostólicas de vida activa después, surge un nuevo tipo de asociación que es solamente de elite y cuyo objetivo es la regeneración social del pueblo. Es una nueva forma de vivir la caridad cristiana en el sentido que va hacia los pobres y que busca regenerarlos a través de la educación y la salud.

Estas tres formas de asociación conviven y no se excluye entre sí. Un selecto grupo de la elite santiaguina pertenece a todas ellas simultáneamente. Las elites no abandonan las cofradías, sino que diversifican sus formas de asociación, pero la cofradía tiende a ser desplazada del centro por las asociaciones piadosas y de beneficencia. Quizás la pregunta principal ante este cambio es a qué tipo de integración social obedecen. Así como las cofradías coloniales suelen ser interpretadas como una forma de integración ritual de la diversidad étnica, una forma de evangelización indígena, creemos que estas dos nuevas obedecen a los inicios de procesos de industrialización y urbanización. Las asociaciones piadosas congregan a un pueblo urbano muy amplio y los asociados entre sí mantienen lazos voluntarios de participación ritual sin vínculo contractual. Tienden a ser mayoritariamente femeninas. Las socie-

(10) Pilar Martínez López Cano, Gisela von Wobeser, Juan Guillermo Muñoz, Cofradías, capellanías y obras pías en la América colonial, Universidad Nacional Autónoma de México, México, 1999. 
dades de beneficencia son una nueva forma de vincularse de la elite con los pobres. El sentido que tiene esta formación de los vínculos me parece esencial y no tengo más que especulaciones. En la cofradía, la elite protege al pobre propio, lo protege a través de un servicio ritual y a veces también monetario. Pero ese pobre no es el indigente, no es el vagabundo ni el mendigo, es un pobre incorporado a la estructura del orden social. Las sociedades de caridad salen hacia los pobres, a regenerar a los pobres verdaderos y a encerrar a los pobres falsos que son los vagabundos, indigentes, etc. Se mantiene el vínculo de protección para la salvación propia, pero se busca integrar al pobre al orden social productivo.

En este sentido, las nuevas asociaciones generan nuevas segregaciones: las sociedades de caridad son solo de la elite y son mayoritariamente masculinas. Las cofradías eran en su mayoría mixtas y socialmente integradas en la fiesta.

Por último, la historia de estas asociaciones muestran el triunfo de la jerarquía eclesiástica en su control y disciplinamiento de los fieles, en la consolidación de la parroquia como centro pastoral y en su capacidad de reciclar sus formas de participación en una sociedad secular. Las nuevas sociedades tendrán por objeto la caridad y junto con ella la defensa del catolicismo y de la Iglesia a través de la educación, de la prensa, de la política. La formación del Estado liberal transformó muy seriamente los vínculos jurídicos entre los asociados de cualquier naturaleza, ello por el sentido y el valor de las sociedades comerciales. El Código Civil les daba una nueva forma de autonomía: eran sociedades con personalidad jurídica que podían administrar sus propios fondos (11). Pero estas sociedades no buscaban autonomía, muy por el contrario, buscaban el fortalecimiento de la Iglesia, del Papa y de los obispos para enfrentar la primera ola secularizadora. Por ello, en sus propios estatutos establecerán su dependencia eclesiástica. Las cofradías (incorporo en este concepto a las asociaciones piadosas), sin personalidad jurídica, operan bajo la propia Iglesia, institución de derecho público igual que las congregaciones en el derecho chileno. Ambas le permitieron al catolicismo chileno tener una fuerte presencia en el nuevo espacio público, aquel espacio público plural creado por el Estado liberal.

El espacio religioso ineractúa con el público de formas diversas. En lo recién visto, pasa a formar parte de la sociedad civil. ¿Significa ello una privatización de la religión? Sí, desde la perspectiva de un régimen de cristiandad. No, desde la perspectiva de la reclusión de la religión a la vida doméstica y a la conciencia individual.

\section{LA PIEDAD MODERNA Y LA DISCIPLINA PRODUCTIVA}

La Iglesia temía esa privatización "moderna” a la vez que también temía los excesos de las manifestaciones públicas de la piedad barroca. Mucho antes del ascenso del liberalismo, sentía un gran temor por los desbordes profanos especialmente, aunque no solo, en los sectores populares. A mediados del siglo XVIII la monarquía borbónica inició una serie de reformas para fortalecer el poder central de la Corona y el regalismo dentro de la Iglesia. Expulsó a los jesuitas, propició la

(11) Código Civil, artículo 557. 
reforma de las Órdenes religiosas y de los seminarios, renovó los estudios e intentó por todos los medios disciplinar las costumbres rituales de los fieles (12). En Chile, dicha reforma tuvo débiles resultados (13). El catolicismo tridentino había arraigado profundamente en América en su sentido ritual -eso era el barroco- pero menos en el sentido de la disciplina religiosa en la práctica de los fieles. Ese fue el centro de la crítica de la corriente de la ilustración católica al interior de la Iglesia en el siglo XVIII y que fue continuada por la jerarquía eclesiástica en el siglo XIX. La reforma en ese período comprendió elevar la relevancia de la parroquia, la predicación, el uso de la lengua vernácula, la reforma de los estudios de los seminarios, la reforma de la vida conventual, el fomento de congregaciones de vida activa y de la caridad como práctica religiosa y la crítica a la religiosidad barroca en contraposición a una fe más internalizada y más activa en el mundo (14).

La Iglesia ultramontana combatió en todo el continente en contra del Estado liberal, pero coincidía con este en un factor esencial que ha sido poco mencionado: la regeneración y la educación del pueblo a través del disciplinamiento individual, del valor del autocontrol, del trabajo y de la obediencia.

Un extraordinario ejemplo -muy poco conocido- lo brinda la política del Arzobispo de Santiago de llevar a Chile a las congregaciones francesas femeninas de vida activa y misioneras nacidas en su mayoría en contra de la Revolución Francesa. Llegaron a mediados de siglo para hacerse cargo de la educación de las mujeres de la elite, de la formación de la Escuela Nacional de Preceptoras, y de los emergentes problemas sociales de la sociedad urbana: los enfermos, pobres y viejos que se refugiaban en hospitales y asilos, de los enfermos en sus propios domicilios, de los presos, de las prostitutas y vagabundas a quienes preparaban para el trabajo artesanal. En Chile solo habían conventos contemplativos. No se conocían religiosas que anduvieran por las calles ni menos que trabajaran. La vida religiosa de las mujeres de la elite era intensamente ritual y un pequeño sector de ellas, ligadas a la corriente de la Ilustración Católica, formaron una sociedad de apoyo a estas nuevas congregaciones y fueron aliadas de la jerarquía en hacer de estos conventos, en contraposición a los coloniales, el modelo de la vida religiosa femenina (15).

La relación de las religiosas francesas con la sociedad chilena, con la jerarquía eclesiástica y con las autoridades públicas, con las mujeres de la elite y con los pobres de la ciudad, relatado en sus diarios de viaje, muestra con una riqueza única el encuentro entre dos formas de devoción, entre una fe individualizada, interiorizada y austera propia de la Contrarreforma o de una reforma católica ya asimilada, que ha asumido el impacto de la Ilustración y del racionalismo y una fe colectiva, pública y emocional propia del Barroco. A estas mujeres francesas, todo les pareció caótico, desde la forma

(12) David Brading, "Tridentine Catholicism and Enlightened Despotism in Bourbon Mexico". Journal of Latin American Studies, n. 15, 1983, pp. 22.

(13) Javier González Echenique, "Manuel de Alday y Expée", en Carlos Oviedo Cavada, Episcolpologio Chileno. 1561-1815, Ediciones Universidad Católica, Santiago, XXXX, T. II.

(14) Antonio Rehbein, "El clero diocesano y su presencia evangelizadora en Chile durante el siglo XIX”, Anuario de la Historia de la Iglesia en Chile, Vol.8,1999; Fernando Aliaga Rojas, "Aporte de la Mujer en el Siglo XIX", Anuario..., Vol.13,1995; Marciano Barrios, La espiritualidad chilena en tiempos de Sor Teresa de Los Andes, Santiago, San Pablo, 1994.

(15) Sol Serrano (ed.), Vírgenes Viajeras. Diarios de religiosas francesas en su ruta a Chile 18381874, Ediciones Universidad Católica, Santiago de Chile, 2000. 
en que se vivía la clausura en los conventos femeninos, hasta las condiciones infrahumanas en que vivían enfermos y delincuentes, el desprecio por el trabajo de las niñas de la elite, el despliegue ceremonial y la gran devoción de todos los sectores sociales. Hacia finales de siglo, las congregaciones de vida activa habían consolidado su obra. Ellas no solo educaron a casi a todas las mujeres escolarizadas de la elite, sino que introdujeron un tipo de piedad romántica que si bien era emotiva, era enteramente controlada y nada tenía de la flagelación y exteriorización barroca. La celebración del mes de María, de la primera comunión, del culto a la Inmaculada Concepción, al Sagrado Corazón, a la Medalla Milagrosa, a la Virgen de Lourdes, arraigaron en todos los sectores sociales y convivieron con cultos y fiestas más antiguas. Ellas organizaron en asociaciones piadosas a mujeres ricas y pobres para la mantención del culto mariano y para las obras de caridad y desplazaron rotundamente a los conventos contemplativos como modelo de religiosidad femenina. Es la piedad barroca y el tipo de convento que la expresaba lo que decae, mientras florece y crece el nuevo modelo congregacionista de vida activa. Ellas marcan una tendencia hacia una fe más individualizada e intramundana, a una feminización de la religión, que estaba en sintonía con muchos de los otros cambios que empezaba a vivir la sociedad como la industrialización, la urbanización, la alfabetización.

FINAL

La privatización del catolicismo barroco fue parcial y muchas de sus expresiones culturales siguen vivas en el continente, pero ello no debe hacer ignorar que ante la separación de las esferas religiosa y secular el catolicismo chileno mantuvo su publicidad como una de las fuerzas de la sociedad civil y mantuvo su fuerza en la esfera privada principalmente a través de las mujeres. La privatización del catolicismo barroco fue la publicidad del catolicismo moderno.

\section{RESUMEN}

La relación entre espacio público y espacio religioso desde la perspectiva de la historia política requieren dos enfoques complementarios: el primero es que la política moderna, al separar el espacio público del privado, tiende a privatizar la religión y hacerla parte del dominio de la conciencia y de la práctica privada. El segundo es que la laicización del Estado en el XIX transforma el rol de la religión que se inserta de distinta forma en el espacio público moderno. En este breve artículo quisiérarnos ejemplificar estos dos enfoques en el caso chileno luego de una crítica a las visiones clásicas sobre el tema. Estudia el establecimiento de la libertad de culto; la nueva inserción del catolicismo en la sociedad civil a través de asociaciones modernas y finalmente las transformaciones en las formas de piedad religiosa.

\section{ABSTRACT}

From the perspective of political history, the relation between the public sphere and religion need requires a complementary approach. The first one is modern politics, which 
attempts to separate the public space from the private one reducing religion to the domain of one's own conscience and private practice. The second approach is the process towards a more lay state in the XIX c. which changes the role of religion, involving it in the public space in quite a different way. This brief article shows these two approaches in the case of the Chilean society, and then provides a critical view on the issue. It deals with the freedom of cult, the new insertion of Catholicism in the civil society through modern associations and finally the transformations in the forms of religious piety. 